\title{
Arsenic Methylation in Soils and Its Relationship with Microbial arsM Abundance and Diversity, and As Speciation in Rice
}

\author{
Fang-Jie Zhao, ${ }^{\dagger, \ddagger * *}$ Eleanor Harris, ${ }^{\ddagger}$ Jia Yan, ${ }^{\S}$ Jincai Ma, ${ }^{\prime \prime}$ Liyou Wu, $\|$ Wenju Liu, ${ }^{\ddagger} \perp$ Steve P. McGrath, \\ Jizhong Zhou," and Yong-Guan $\mathrm{Zhu}^{\text {§,\# }}$ \\ $\dagger$ Jiangsu Collaborative Innovation Center for Solid Organic Waste Resource Utilization, College of Resources and Environmental \\ Sciences, Nanjing Agricultural University, Nanjing 210095, China \\ ${ }^{\ddagger}$ Sustainable Soil and Grassland Systems Department, Rothamsted Research, Harpenden, Hertfordshire AL5 2JQ, U.K. \\ ${ }^{\S}$ Research Center for Eco-Environmental Sciences, Chinese Academy of Sciences, Beijing 100085, China \\ "Institute for Environmental Genomics, University of Oklahoma, Norman, Oklahoma 73019, United States \\ ${ }^{\perp}$ College of Resources and Environmental Science, Hebei Agricultural University, Baoding, Hebei Province 071001, China \\ ${ }^{\#}$ Key Laboratory of Urban Environment and Health, Institute of Urban Environment, Chinese Academy of Sciences, Xiamen 361021, \\ China
}

\section{Supporting Information}

\begin{abstract}
Methylation of arsenic in soil influences its environmental behavior and accumulation by plants, but little is known about the factors affecting As methylation. As speciation was determined in the pore waters of six soils from diverse geographical locations over 54 days of incubation under flooded conditions. The concentration of methylated As (monomethylarsonic acid, MMA, and dimethylarsinic acid, DMA) varied from 0 to $85 \mu \mathrm{g} \mathrm{L}^{-1}(0-69 \%$ of the total As in pore water). Two Bangladeshi paddy soils contaminated by irrigation of As-laden groundwater produced large concentrations of inorganic As but relatively little methylated As. Two contaminated paddy soils from China produced a transient peak of DMA during the early phase of incubation. Methylated As represented considerable proportions of the total soluble As in the two uncontaminated soils from the UK and U.S. The copy number of the microbial arsenite methyltransferase gene $(\operatorname{ars} M)$ correlated positively with soil $\mathrm{pH}$. However, pore-water methylated As correlated negatively with $\mathrm{pH}$ or $\operatorname{ars} \mathrm{M}$ copy number, and positively with dissolved organic C. GeoChip assay revealed considerable ars $M$ diversity among the six soils, with 27-35 out of 66 sequences in the microarray being detected. As speciation in rice plants grown in the soils generally mirrored that in the pore water. The results suggest that methylated As species in plants originated from the soil and As methylation in soil was influenced strongly by the soil conditions.
\end{abstract}

\section{INTRODUCTION}

Arsenic (As) is a ubiquitous contaminant in the environment originating from both natural and anthropogenic sources. Because its biogeochemical behavior and toxicity vary greatly among different chemical species, it is important to understand how the speciation of As changes in the environment and what drives such changes. A particularly important case is the paddy rice system because it is now recognized that rice is a major source of As in the human diet. ${ }^{1}$ The anaerobic conditions in paddy soils are conducive to the mobilization of arsenite, ${ }^{2,3}$ which is taken up inadvertently by rice roots through the strong uptake pathway for silicic acid. ${ }^{4}$ Rice grain contains both inorganic As (arsenate and arsenite) and organic As (mostly dimethylarsinic acid, DMA; occasionally also trace amounts of monomethylarsonic acid, MMA, and tetramethylarsonium). ${ }^{5-9}$ As speciation in rice varies widely among different riceproducing regions. Market-basket surveys show that Asian rice generally is dominated by inorganic As with DMA typically accounting for about $20 \%$ of the total As. ${ }^{5-7,10}$ In contrast, rice produced in the U.S. and Europe is more variable in As speciation with many samples containing more organic than inorganic As. ${ }^{5,7,8,10}$ It is possible that that this geographical pattern reflects the relative bioavailability of inorganic versus organic As in different paddy environments. ${ }^{10}$ Compared with inorganic As, methylated As species are more easily accumulated in rice grain. ${ }^{10}$ Although pentavalent methylated As species are less toxic than inorganic As to animals and human cells, trivalent methylated As species are more toxic. ${ }^{11}$ Methylated As species are also implicated in the physiological disorder "straight-head" disease in rice, ${ }^{1}$ causing spikelet sterility and yield losses. ${ }^{12}$

Methylated As species have been found in soils, usually as minor species compared to the predominance of inorganic

Received: December 5, 2012

Revised: $\quad$ May 26, 2013

Accepted: June 10, 2013

Published: June 10, 2013 
As. ${ }^{13-17}$ Methylated As in soil may originate from anthropogenic sources (e.g., the widespread uses of mono- or disodium salts of MMA and DMA as herbicides and pesticides in the U.S.), atmospheric deposition and methylation mediated by soil microbes; ${ }^{17}$ the latter is likely to be the main source where methyl arsenicals have not been used. Methylation of As in soil is strictly a biological process since no methylation was found when soil was sterilized with formaldehyde. ${ }^{18}$ Arsenic methylation appears to be particularly strong in peatland during the period when microbial activity was high and the redox conditions were reducing. ${ }^{14}$ In contrast, DMA disappeared from the pore water when a peaty soil became aerobic. ${ }^{19}$ Takamatsu et al. ${ }^{13}$ found more methylated As in paddy soils than in upland orchard soils, suggesting that the paddy anaerobic conditions may favor As methylation. Methylated As species can be reduced to methylarsine gases and volatilized. ${ }^{20-22}$ This process is also enhanced by anaerobic conditions in the soil. ${ }^{20,21,23}$

Many soil microorganisms are able to methylate As. ${ }^{22}$ Methylation is catalyzed by the arsenite methyltransferase (arsM) enzyme. ${ }^{24-26}$ When arsM gene from the soil bacterium Rhodopseudomonas palustris was expressed in an As-sensitive Escherichia coli strain, the $E$. coli produced a number of methylated As compounds with volatile trimethylarsine as the end product and became more resistant to arsenite in the medium, suggesting that As methylation is a detoxification mechanism. ${ }^{25}$ The function of arsM genes has also been demonstrated in a number of eukaryotic algae. ${ }^{24,27}$ The amino acid sequences of arsM from divergent organisms are highly conserved, with three strictly conserved cysteine residues being involved in the catalytic function. ${ }^{26,28}$ Lomax et al. ${ }^{29}$ used a microarray-based technique (GeoChip 4.0$)^{30}$ to detect microbial functional genes involved in As transformation in a contaminated paddy soil from Bangladesh. Thirty-five of the 66 ars $M$ sequences included in the array were detected. Using a most probable number method, Islam et al. ${ }^{31}$ estimated that there were $0.2-7.8 \times 10^{4}$ As methylating bacteria per gram of soil in 10 As contaminated soils from Bangladesh. However, there is little information regarding the abundance and diversity of As methylating microbes and their relationship to As methylation activity across different soils.

The objectives of the present study were to investigate the dynamics of As speciation, especially of methylated As, in the pore water of soils from diverse geographical origins, and to examine the relationships between As methylation in soil, soil properties, and the abundance and diversity of microbial ars $M$ genes. A further objective was to relate As speciation in soil to that in rice plants.

\section{MATERIALS AND METHODS}

Soils. Six soils were used in the present study: two paddy soils from Bangladesh (BD1, BD2) that have been contaminated with As from irrigation of groundwater, two paddy soils from south-central China $(\mathrm{CN} 1, \mathrm{CN} 2)$ that have elevated As concentrations due to nearby mining activities or geogenic reasons, and two upland arable soils from the UK and U.S. that have no known history of As contamination (Supporting Information (SI) Table S1). Soils were air-dried and sieved to $<6 \mathrm{~mm}$. Selected soil properties, such as $\mathrm{pH}$, organic $\mathrm{C}$, total $\mathrm{N}$, total As, and phosphate-extractable As concentrations, were determined following standard methods of soil analysis. ${ }^{32}$

Incubation and Plant Growth Experiments. The six soils were first incubated under flooded conditions in the UK laboratory to determine As mobilization and speciation in soil pore water. Triplicate of $500 \mathrm{~g}$ soil were placed in plastic pots and flooded with deionized water to maintain a $2 \mathrm{~cm}$ layer of standing water above the soil surface. A Rhizon soil solution sampler was inserted to each pot for the collection of soil pore water at $5,10,15,20,30$, and 54 days after flooding. Soil pore water was acidified to $\mathrm{pH}<2$ with $\mathrm{HCl}(10 \mathrm{~mL}$ solution with $0.1 \mathrm{~mL}$ concentrated $\mathrm{HCl}$ ) and filtered through a sterilized 0.2 $\mu \mathrm{m}$ filter before analysis of As speciation. A preliminary test was carried out to compare the pore water preservation methods with either EDTA (e.g., refs 2 and 33) or $\mathrm{HCl}$ (e.g., ref 34) using the UK soil. Both methods have been used to prevent iron precipitation and changes in As speciation in groundwater or soil pore water samples. The results showed that there was no significant difference between the two methods in the As(III) or As (V) concentrations, but the DMA concentration was 5 fold higher in the $\mathrm{HCl}$-preserved samples than in the EDTA-preserved ones (SI Figure S1). Therefore, the $\mathrm{HCl}$ method performed better at preserving small concentrations of methylated As species in soil solutions and was used in the present study.

Arsenic species were quantified using anion exchange HPLCICP-MS (Agilent LC1100 series and Agilent ICP-MS 7500ce, Agilent Technologies, Santa Clara, CA) as described previously. ${ }^{2}$ A subset of pore water samples were analyzed for total soluble As using ICP-MS (Agilent ICP-MS 7500ce). The sum of As species determined by HPLC-ICP-MS was found to agree with the total As determined by ICP-MS (SI Figure S2). Soil redox potential (Eh) was measured at approximately 0.5 $\mathrm{cm}$ below the soil surface using a combined platinum and silver/silver chloride electrode system. Dissolved organic C (DOC) was measured in the pore water samples collected on day 30.

On day 30, four pregerminated rice seedlings (cv. Italica carolina) were transplanted into each pot. All pots were placed inside a glasshouse (day/night temperatures $28 / 25{ }^{\circ} \mathrm{C}$, light period $16 \mathrm{~h}$ per day with natural sunlight supplemented with sodium vapor lamps to maintain a light intensity of $>350 \mu \mathrm{mol}$ $\mathrm{m}^{-2} \mathrm{~s}^{-1}$ ). Plants were harvested on day 54 by cutting the aboveground part, rinsed with deionized water, and frozen in liquid nitrogen. Plant samples were ground to fine powder in liquid nitrogen, and extracted with a phosphate buffer solution $(2 \mathrm{mM}$ $\mathrm{NaH}_{2} \mathrm{PO}_{4}$ and $0.2 \mathrm{mM} \mathrm{Na}$-EDTA, $\mathrm{pH}$ 5.5) for $1 \mathrm{~h}$ under sonication in a cold room $\left(4{ }^{\circ} \mathrm{C}\right) .{ }^{35}$ The extract was filtered through No.42 Whatman filter paper, followed by filtration through $0.2 \mu \mathrm{m}$ and then analyzed for As speciation using anion exchange HPLC-ICP-MS. ${ }^{35}$

Determination of Bacterial 16S rDNA and arsM Copy Number. Distilled water $(6 \mathrm{~mL})$ was added to $10 \mathrm{~g}$ air-dried soil and incubated at $30{ }^{\circ} \mathrm{C}$ in the dark for 2 weeks when microbial biomass had reached a steady state. Total microbial DNA was extracted from the soils using the FastDNA SPIN Kit for Soil (MP Biomedicals, Santa Anna, CA) and the FastPrep Instrument (MP Biomedicals), following the manufacturer's instructions. DNA concentration was measured with Nanodrop ND-1000 UV-Vis spectrophotometer (NanoDrop Co., Wilmington, DE). Real time PCR (qPCR) was used to determine the bacterial $16 \mathrm{~S}$ rDNA copy number as a measure of bacterial abundance. Each reaction mixture $(25 \mu \mathrm{L})$ contained $12.5 \mu \mathrm{L}$ premix Ex-taqTM (TaKaRa), $1 \mu \mathrm{L}$ DNA template (after 10fold dilution of the soil DNA extracts), $1 \mu \mathrm{L}$ of each $10 \mu \mathrm{M}$ primer pair and $0.5 \mu \mathrm{L} \quad 10 \mu \mathrm{M}$ probe (TM1389F CTTGTACACACCGCCCGTC). qPCR was performed on 

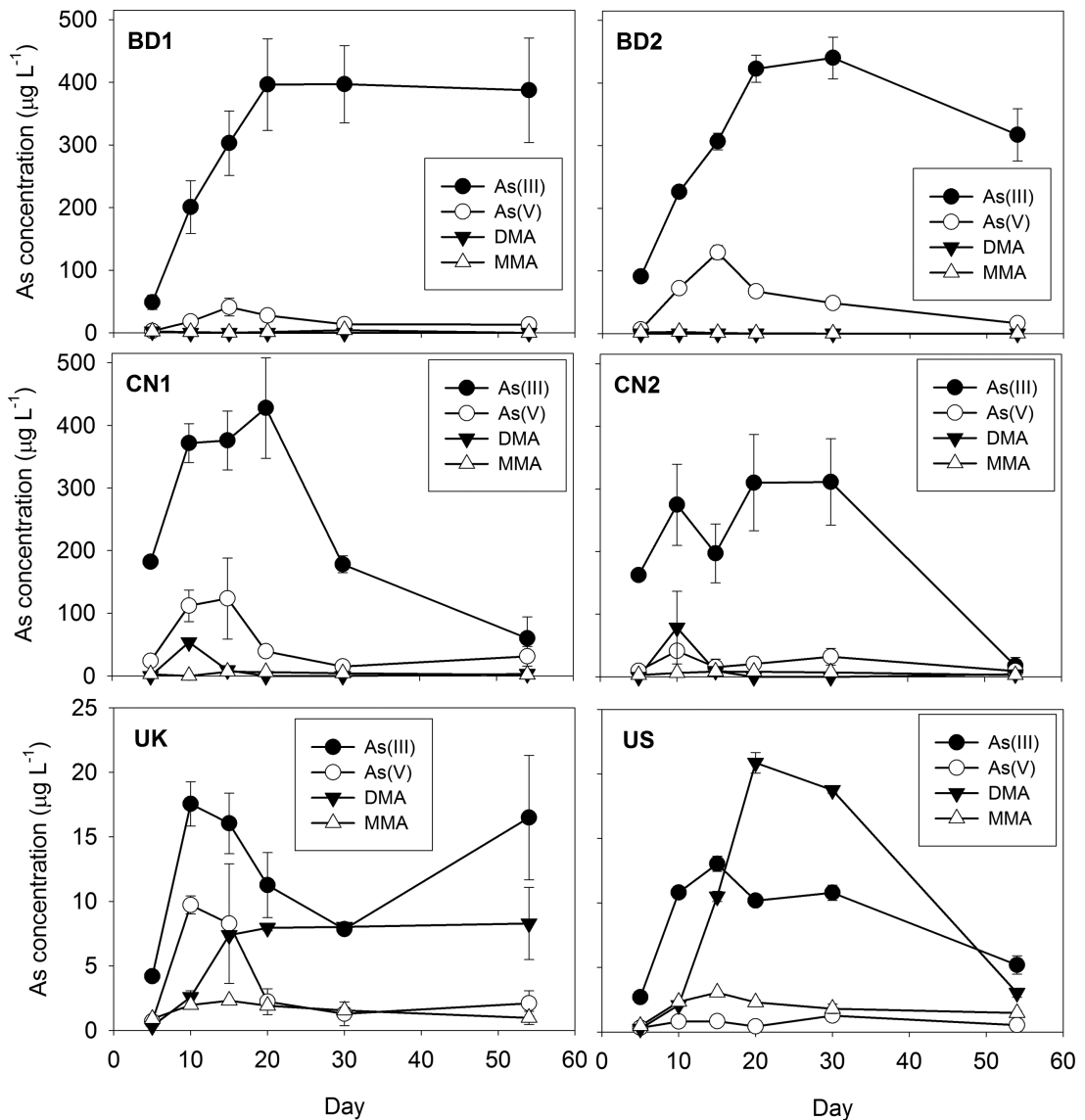

Figure 1. Dynamics of As speciation in soil pore water after incubation under flooded conditions. Rice seedlings were grown between days 30 and 54. Data are means \pm SE. Soil codes: BD1, Faridpur, Bangladesh; BD2, Sonargaon, Bangladesh; CN1, Chenzhou, China; CN2, Qiyang, China; UK, Rothamsted, UK; U.S., Athens, GA. Arsenic species: As(III), arsenite; As(V), arsenate; MMA, monomethylarsonic acid; DMA, dimethylarsinic acid.

an iQTM5 thermocycler (BioRad, Hercules, CA) with the following cycling parameters: $95{ }^{\circ} \mathrm{C}$ for $10 \mathrm{~s}$, followed by 35 cycles at $95{ }^{\circ} \mathrm{C}$ for $15 \mathrm{~s}$ and at $56{ }^{\circ} \mathrm{C}$ for $1 \mathrm{~min}$. The bacterial standard template DNA was prepared by PCR amplified $16 \mathrm{~S}$ rDNA using bacteria-specific primer pair (27F/1492R). The PCR amplicons were ligated into pGEM-T Easy vector (Promega, Fitchburg, WI) and the resultant plasmids were transformed into E.coli JM109 cells. Plasmid DNA was extracted and the concentration was measured with Nanodrop ND-1000 UV-vis spectrophotometry (NanoDropCo.).These plasmids were then sequenced and used as an internal standard for qPCR.

To determine the abundance of ars $M$ gene, soil DNA was diluted by 10 -fold and subjected to qPCR using an iQTM5 Thermocycler (Bio-Rad). Each $25 \mu \mathrm{L}$ reaction mixture contained 12.5 $\mu \mathrm{L}$ SYBR Premix Ex-TaqTM (Takara Bio Inc., Japan), $1 \mu \mathrm{L}$ DNA template (after 10-fold dilution of the soil DNA extracts), and $1 \mu \mathrm{L}$ of each $10 \mu \mathrm{M}$ primers arsMF/ arsMR (arsMF: TCYCTCGGCTGCGGCAAYCCVAC; arsMR: CGWCCGCCWGGCTTWAGYACCCG). ${ }^{36}$ The thermal cycling parameters were as follows: $95{ }^{\circ} \mathrm{C}$ denatured 10 min, followed by 40 cycles at $95{ }^{\circ} \mathrm{C}$ for $30 \mathrm{~s}, 60^{\circ} \mathrm{C}$ for $45 \mathrm{~s}, 72$ ${ }^{\circ} \mathrm{C}$ for $1 \mathrm{~min}$; and a final extension at $72{ }^{\circ} \mathrm{C}$ for $10 \mathrm{~min}$. Melting curve analysis was performed at the end of PCR runs to check the specificity of the amplification. The standard template DNA was prepared using specific primer pair to amplify ars $M$ genes. The PCR amplicons were ligated into pGEM-T Easy vector (Promega) and the resultant plasmids were transformed into $E$. coli JM109 cells. The positive clones with the target gene insert were sequenced and the most abundant one was subject to plasmid DNA extraction. After concentration measurement with Nanodrop ND-1000 UV-Vis spectrophotometer (NanoDrop Co.), the purified plasmid DNA were serially 10-fold diluted and subjected to real-time PCR in triplicate to generate an external standard curve.

Geochip Assay. A microbial functional gene array GeoChip $4.0{ }^{30}$ synthesized by Nimblegen (Madsion, WI) in their 12 plex format was used for detecting genes involved in As transformation in the soils. Soil sample $(10 \mathrm{~g})$ was taken from each incubation pot on day 30 and placed on dry ice. Microbial community DNA was extracted from $5 \mathrm{~g}$ soil by freeze-grinding mechanical lysis as described previously ${ }^{37}$ and was purified using a low melting agarose gel followed by phenol extraction. The purified DNA $(1 \mu \mathrm{g})$ was labeled with Cy-3 dye and then hybridized at $42{ }^{\circ} \mathrm{C}$ for $16 \mathrm{~h}$ on a Hybridization Station (MAUI, BioMicro Systems, Salt Lake City, UT). Spots with low signal intensity $(<1000)$ or poor signal-to-noise ratio (signal intensity-local background)/standard deviation of slide background $<2.0$ )were removed. Signal intensity of each spot was then normalized by the mean intensity of the slide. The quantified microarray data were preprocessed as described previously. $^{30}$

\section{RESULTS}

Soil Properties. The six soils used in the present study varied widely in total As concentrations, ranging from 3 to 81 
$\mathrm{mg} \mathrm{kg}^{-1}$ (SI Table S1). Phosphate-extractable As represented $4-31 \%$ of the total As; the extractability was low $(\sim 5 \%)$ in the UK and U.S. soils, intermediate $(\sim 10 \%)$ in the two Chinese paddy soils, and high (15-30\%) in the two paddy soils from Bangladesh. Soil $\mathrm{pH}$ varied from 4.8 to 8.2 . The concentrations of dissolved organic C (DOC) in the soil pore waters collected after 30 days of incubation under flooded conditions were high in the UK and U.S. soils $\left(500-509 \mathrm{mg} \mathrm{L}^{-1}\right)$, intermediate in the two Chinese soils $\left(106-156 \mathrm{mg} \mathrm{L}^{-1}\right)$ and relatively low in the two Bangladeshi soils (32-68 $\mathrm{mg} \mathrm{L}^{-1}$ ). Soil redox potential, measured near the soil surface, dropped to below $300 \mathrm{mV}$ on day 5 and decreased further to between 50 and $190 \mathrm{mV}$ on day 30 (SI Figure S3).

As Species Dynamics in Soil Pore Water. Arsenic concentration in soil pore water increased after soil flooding and peaked between day 10 and 30 depending on the soil (Figure 1). The soils from both Bangladesh and China produced high concentrations of total soluble As (400-500 $\left.\mu \mathrm{g} \mathrm{L}^{-1}\right)$ in their pore water at the peak of mobilization, whereas the concentrations were about an order of magnitude lower in the soils from the U.S. and UK. The scale of As mobilization generally agreed with the amount of phosphate-extractable As in the same soils. The concentration of pore-water As decreased markedly during the later phase of incubation or during the period of rice growth (from day 30 to 54) in some of the soils, especially in the two Chinese soils.

The dynamics of As species in the pore water differed among the soils studied (Figure 1). In the two Bangladeshi soils, arsenite was the predominant species. Small concentrations (0.2-4.4 $\left.\mu \mathrm{g} \mathrm{L}^{-1}\right)$ of MMA was detected throughout the incubation, while DMA was not detectable in either soils except $\mathrm{BD} 1$ on day $5\left(2.6 \mu \mathrm{g} \mathrm{L}^{-1}\right)$. Due to the high concentrations of total soluble As, methylated As species were only minor species in these two soils, accounting for $<5 \%$ (mostly $<1 \%$ ) of the total As in the pore water. Arsenite was also the predominant As species in the two Chinese paddy soils, although small concentrations of MMA (1.6-8.4 $\left.\mu \mathrm{g} \mathrm{L}^{-1}\right)$ were also detected and considerable amounts of DMA $\left(54-79 \mu \mathrm{g} \mathrm{L}^{-1}\right)$ were found on day 10. The concentrations of DMA then decreased to between 0 and $10 \mu \mathrm{g} \mathrm{L}^{-1}$. MMA and DMA accounted for $0-$ $10.4 \%$ and $0-20.2 \%$, respectively, in the pore water samples from the two Chinese paddy soils. Despite relatively low concentrations of total soluble As in the UK and US soils, MMA (0.5-2.7 $\left.\mu \mathrm{g} \mathrm{L}^{-1}\right)$ and DMA $\left(0.3-21 \mu \mathrm{g} \mathrm{L}^{-1}\right)$ were detectable in all sampling times. In the U.S. soil, DMA concentration reached a peak $\left(21 \mu \mathrm{g} \mathrm{L}^{-1}\right)$ on day 20 , followed by a gradual decrease to $3 \mu \mathrm{g} \mathrm{L}^{-1}$ on day 54. MMA and DMA accounted for $6-15 \%$ and $7-62 \%$, respectively, of the total soluble As in the U.S. soil pore water; the latter was the predominant As species (>50\%) on days 20 and 30. In the UK soil, MMA concentration was relatively stable $\left(0.9-2.3 \mu \mathrm{g} \mathrm{L}^{-1}\right)$ throughout the incubation, while DMA concentration reached a peak $\left(8 \mu \mathrm{g} \mathrm{L}^{-1}\right)$ on day 20 and remained at this level during the subsequent sampling times. MMA and DMA accounted for 3$14.7 \%$ and $5-36 \%$ of the total soluble As in the UK soil pore water.

Gene Copy Numbers of Bacterial 16S rDNA and arsM. Bacterial $16 \mathrm{~S}$ rDNA copy number, reflecting the abundance of bacteria in the soils, varied from 2.6 to $12.9 \times 10^{10} \mathrm{~g}^{-1}$ dry soil (Table 1). A highly significant correlation between $16 \mathrm{~S}$ rDNA copy number and soil $\mathrm{pH}$ was found $(r=0.96, P<0.01$; SI Figure S4); thus, the low $\mathrm{pH}$ in the U.S. soil may explain its low bacterial abundance. The copy number of the ars $M$ gene varied
Table 1. Gene Copy Numbers (Means \pm SE) of Bacterial $16 S$ rRNA and Arsenic Methyltransferase $\operatorname{ars}^{a}$

$\begin{array}{cccc}\text { soil } & \begin{array}{c}\text { 16S rRNA }\left(10^{10} \mathrm{~g}^{-1}\right. \\ \text { dry soil })\end{array} & \begin{array}{c}\operatorname{ars}\left(10^{7} \mathrm{~g}^{-1} \text { dry }\right. \\ \text { soil })\end{array} & \begin{array}{c}\operatorname{ars} M / 16 S \text { rRNA ratio } \\ \left(\mathrm{x} 10^{-3}\right)\end{array} \\ \text { BD1 } & 12.56 \pm 0.34 & 2.26 \pm 0.18 & 0.18 \pm 0.02 \\ \text { BD2 } & 9.66 \pm 0.32 & 2.35 \pm 0.24 & 0.24 \pm 0.02 \\ \text { CN1 } & 12.90 \pm 1.80 & 1.46 \pm 0.15 & 0.11 \pm 0.00 \\ \text { CN2 } & 11.06 \pm 1.69 & 1.64 \pm 0.16 & 0.15 \pm 0.02 \\ \text { UK } & 8.21 \pm 0.99 & 1.51 \pm 0.25 & 0.19 \pm 0.05 \\ \text { US } & 2.58 \pm 0.15 & 0.37 \pm 0.04 & 0.14 \pm 0.02\end{array}$

${ }^{a}$ See Figure 1 caption for the soil codes.

from 0.4 to $2.3 \times 10^{7} \mathrm{~g}^{-1}$ dry soil, being lowest in the U.S. soil and highest in the two Bangladeshi soils (Table 1). The copy numbers of ars $M$ gene also correlated positively with soil $\mathrm{pH}(r$ $=0.90, P<0.05$; SI Figure S4). While ars $M$ copy number varied by 6 fold among the six soils, the ratio of ars $M$ to $16 \mathrm{~S} \mathrm{rDNA}$ varied by only 2 fold.

Correlation analysis was performed on the data set between the sum of MMA and DMA in the soil pore water collected on days 20 and 30 (when As mobilization peaked) and other soil measurements. Surprisingly, the concentrations of methylated As species correlated significantly but negatively with arsM copy number $(r=-0.93$ to $-0.98, P<0.01$; SI Figure S5 for day 30$)$. This may be because methylated As species correlated negatively with soil $\mathrm{pH}(r=-0.91$ to $-0.94, P<0.05$; SI Figure $\mathrm{S5})$, which had a positive correlation with the arsM copy number. There was also a significant and positive correlation between the concentration of methylated As species and DOC $(r=0.82, P<0.05$; SI Figure S5). There was a negative, but not significant $(P=0.062)$, correlation between methylated As and inorganic As concentrations (SI Figure S5).

Geochip Assays. GeoChip 4.0 was used to assess the abundance and diversity of the ars $M$ gene in the six soils. Out of the 68 ars $M$ sequences included in GeoChip, between 27 and 35 sequences were detected in the six soils, among which 26 sequences were detected in all soils (Figure 2). The heat-map shows the relative abundance of the different $\operatorname{ars} M$ sequences detected in the six soils (Figure 2). The average abundance of ars $M$ based on the GeoChip data (Figure 2) was in general agreement with the qPCR data (Table 1). The detected sequences included several sulfur reducing bacteria and Rhodopseudomonas palustris in which the arsenite methyltransferase function of arsM has been demonstrated. ${ }^{25}$ The most abundant arsM sequence across all six soils was that from Desulfohalobium retbaense DSM 5692, whereas sequences from Pelotomaculum thermopropionicum SI, Thioalkalivibrio sp. HLEbGR7, Rhodopseudomonas palustris DX-1, Sphaerobacter thermophilus DSM 20745, Symbiobacterium thermophilum IAM 14863, Thiobacillus denitrificans ATCC 25259, and Treponema vincentii ATCC 35580 were also abundant in all soils. In contrast, $\gamma$-Proteobacterium HTCC5015 and Methanosarcina mazei Gol sequences were detected in the two Bangladeshi soils only. Cluster analysis based on ars $M$ sequences shows that the two Bangladeshi soils separated from the other soils.

Arsenic Speciation in Rice Plants. Arsenic concentration in the rice seedlings ( 24 day old) varied by 18 -fold in the six soils (Table 2), and correlated significantly with the total soluble As in the soil pore water on days 30 (rice transplanting) and 54 (plant harvesting) (SI Figure S6). Arsenite dominated in the rice plants grown on the Bangladeshi and Chinese paddy soils (92-98\% of the total As), whereas arsenate was a minor 


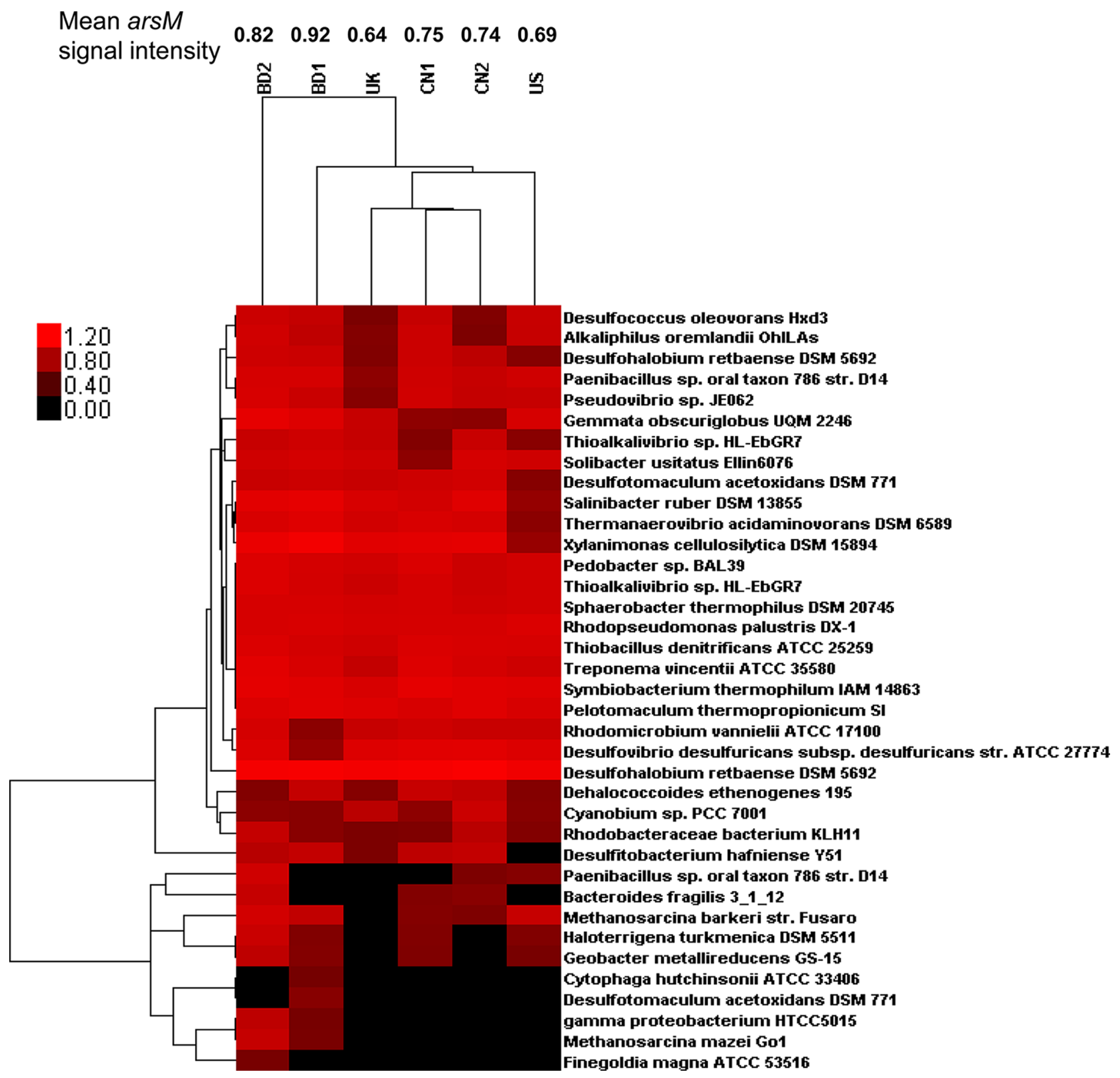

Figure 2. The abundance and diversity of microbial ars $M$ genes in the six soils used in the study, assayed using Geochip 4.0. Values above the soil codes are the normalized mean ars $M$ intensity. See Figure 1 caption for the soil codes.

Table 2. Arsenic Speciation (Means \pm SE) in Rice Seedlings Grown in the Six Soils ${ }^{a}$

\begin{tabular}{ccccc} 
soil & $\begin{array}{c}\mathrm{As}(\mathrm{III})(\mu \mathrm{g} \\
\left.\mathrm{kg}^{-1}\right)\end{array}$ & $\begin{array}{c}\mathrm{As}(\mathrm{V})(\mu \mathrm{g} \\
\left.\mathrm{kg}^{-1}\right)\end{array}$ & $\begin{array}{c}\mathrm{DMA}(\mu \mathrm{g} \\
\left.\mathrm{kg}^{-1}\right)\end{array}$ & $\begin{array}{c}\mathrm{MMA}(\mu \mathrm{g} \\
\left.\mathrm{kg}^{-1}\right)\end{array}$ \\
$\mathrm{BD} 1$ & $955.0 \pm 161.7$ & $18.8 \pm 3.1$ & $0.0 \pm 0.0$ & $0.0 \pm 0.0$ \\
$\mathrm{BD} 2$ & $735.3 \pm 47.1$ & $23.5 \pm 4.3$ & $0.0 \pm 0.0$ & $0.0 \pm 0.0$ \\
$\mathrm{CN} 1$ & $610.9 \pm 5.0$ & $20.0 \pm 4.3$ & $0.0 \pm 0.0$ & $1.3 \pm 1.3$ \\
$\mathrm{CN} 2$ & $367.4 \pm 53.6$ & $27.2 \pm 8.1$ & $0.0 \pm 0.0$ & $2.3 \pm 2.3$ \\
UK & $91.6 \pm 18.2$ & $5.5 \pm 1.0$ & $10.8 \pm 3.4$ & $0.0 \pm 0.0$ \\
US & $51.8 \pm 8.1$ & $7.8 \pm 0.5$ & $20.7 \pm 2.3$ & $14.0 \pm 2.2$ \\
${ }^{a}$ See Figure 1 caption for the soil codes. \\
\multicolumn{5}{l}{}
\end{tabular}

component in all plants $(2-8 \%)$. Methylated As species were not detectable in the plants grown on the two Bangladeshi soils, consistent with no or very little MMA and DMA in these two soils. MMA was detected in the plants grown on the two Chinese soils and on the U.S. soil; the concentration was very small in the former but considerable in the latter. DMA was detected in the plants from the UK and U.S. soils, accounting for 10 and $22 \%$, respectively, of the total As in the plants. The occurrence of DMA in rice seedlings mimicked the presence of DMA in the soil pore water on day 30 (SI Figure S6).

\section{DISCUSSION}

It is well established that anaerobic conditions in soil are conducive to As mobilization due to the reductive dissolution of iron (oxy)hydroxides and the reduction of arsenate to arsenite. ${ }^{2,32,38-40}$ However, different soils exhibited different patterns in the dynamics of pore-water As with some showing a marked decrease following initial mobilization (Figure 1). Decreases in pore-water As after prolonged anaerobic incubation have been observed in some soils before, ${ }^{32,41}$ and may be attributed to the formation and precipitation of 
secondary iron-bearing minerals (e.g., magnetite), resulting in adsorption or coprecipitation of As species. ${ }^{42,43}$

The dynamics of As speciation in soil pore water were complex, showing large variations between different soils and different sampling times (Figure 1). In addition to inorganic As species, various amounts of MMA and DMA were also detected during at least some of the sampling times. The two Bangladeshi paddy soils, contaminated by irrigation of Asladen groundwater, produced large concentrations of inorganic As (predominantly arsenite) in the pore waters, but very little methylated As species, suggesting a low As methylation potential in these soils. The two Chinese paddy soils, both from the south-central Hunan province but containing elevated As due to different reasons, produced a peak of DMA during the early phase of incubation, followed by a rapid decrease during the later phase of incubation, suggesting possible losses of DMA. The two nonpaddy soils from the UK and U.S., both having no history of As contamination, produced proportionally more DMA and MMA than the other soils. In fact, DMA and MMA together accounted for $>50 \%$ of the total soluble As in the U.S. and UK soils during some of the incubation time points.

Because $\operatorname{ars} M$ is the key functional gene responsible for microbial As methylation, ${ }^{24-26}$ it might be expected that As methylation correlates positively with the copy number of this gene. A positive correlation was observed in a recent study investigating the variation of ars $M$ copy number as influenced by the rhizosphere and straw addition in a single soil. ${ }^{36}$ However, the results from the present study, based on six soils from geographically diverse regions, showed an opposite pattern. This surprising result may be explained by several reasons. First, it is the activity, rather than the abundance, of As methylation microbes that determines the As methylation activity, which may in turn depend on the environmental conditions. Indeed, methylated As concentrations were found to correlate significantly and negatively with soil $\mathrm{pH}$, but positively with DOC, whereas the arsM gene copy number correlated positively with soil $\mathrm{pH}$. The data suggest that, although there were more As methylating microbes in neutralalkaline soils (as well as other bacteria shown by the $16 \mathrm{~S} \mathrm{rDNA}$ data), the activity of As methylation was higher in the acidic soils. A previous study showed that the production trimethylarsine by a fungal isolate of Penicillium sp. had an optimal pH range between 5 and $6 .^{44}$ In contrast, CarbonellBarrachina et al. ${ }^{45}$ reported that As methylation in a sewage sludge suspension occurred at $\mathrm{pH} 6.5$ and 8.0, but was drastically restricted at $\mathrm{pH}$ 5.0. The positive correlation with DOC is consistent with previous reports that additions of organic matter stimulated As methylation and the volatilization of methylated As species. ${ }^{20,21,46,47}$ Furthermore, arsM copy number was found to be significantly higher in the rhizosphere soil than in the bulk soil and to be enhanced by the addition of rice straw, ${ }^{36}$ both suggesting a positive effect of organic substrate addition possibly due to increased food source for the As methylation microbes. Soil flooding was found to enhance As methylation in soil ${ }^{21,48}$ and to increase the concentration of DMA in rice grain. ${ }^{2,3,49}$ Because inorganic As is the substrate for methylation, it might be expected that the concentrations of methylated As and inorganic As in soil pore water would correlate with each other. ${ }^{17}$ However, no significant positive correlation was found in the present study. Other soil properties such as the availability of trace elements may also influence microbial As methylation. ${ }^{50}$
Second, there are likely to be many As methylating microbes in soils, ${ }^{31,36}$ some of which may be more active than others in mediating As methylation. Among several anaerobic As methylating microbes isolated from an As-contaminated lake sediment, sulfur-reducing microbes were found to possess the highest ability to methylate As. ${ }^{51}$ The GeoChip assay (Figure 2) revealed considerable diversity in the arsM sequences present in the six soils studied. Similarly, Jia et al. ${ }^{36}$ reported that microbes containing ars $M$ genes were phylogenetically diverse in an As-contaminated paddy soil. There was also an indication of clustering of soils from different geographical regions based on the ars $M$ diversity (Figure 2), although more soils need to be investigated to draw a firm conclusion.

Third, the concentrations of methylated As species in soil pore water reflect the balance between As methylation and the losses of methylated As through either volatilization or demethylation (mineralization). Losses of methylated As through either or both pathways were likely responsible for the rapid decrease of DMA concentration following an early peak observed in some soils (Figure 1). DMA may be reduced to dimethylarsine, or further methylated to form trimethylarsine, both of which are volatile. Mestrot et al. ${ }^{20,21}$ detected a number volatile arsines, including arsine, mono-, di-, and trimethylarsines, in the headspace atmosphere from both laboratory microcosm experiments and field trials, with trimethylarsine being the main arsine species volatilized. Moreover, volatilization was enhanced by anaerobic conditions in soil. ${ }^{21,23}$ In general, volatilization of methylarsine species represents only a very small proportion of the total As in soils. $^{20,21}$ Demethylation of DMA was also observed in soils or soil extracts. ${ }^{52}$ Gao and Burau ${ }^{53}$ showed that both MMA and DMA were mineralized to As $(\mathrm{V})$ when added to a soil, with the latter being mineralized more rapidly than the former. After incubation for 70 days, between 3 and $87 \%$ of methylated As was mineralized, compared with only $0.001-0.4 \%$ being lost as volatile arsines. Thus, mineralization appears to be the main pathway responsible for the losses of methylated As species, especially under aerobic conditions. ${ }^{48,53}$ Mineralization of methylated As species is carried out by microorganisms in soil. Yoshinaga et al. ${ }^{54}$ showed that mineralization of MMA involves two sequential steps, reduction of $\mathrm{MMA}(\mathrm{V})$ to MMA(III) and subsequent demethylation of MMA(III), with the two steps being carried out by two separate microbes belonging to Burkholderia and Streptomyces species, respectively, in soils from golf courses in Florida. Microbes responsible for the mineralization of methylated As species in flooded paddy soils remain unknown.

Arsenic speciation in rice seedlings, especially DMA, was found to mimic that in the soil pore water at the time of transplanting (Table 2 and SI Figure S6). DMA was present in the soil pore waters in the US and UK soils and in the rice plants grown in these soils, but not in the other four soils at the time of transplanting nor in the rice plants. These results support the recent findings that rice plants lack the ability to methylate As and, consequently, methylated As species in rice are derived from the soil. ${ }^{29,47}$ It is interesting to note that the variation among soils in the concentrations of DMA in pore water and in the rice plants found in the present study was in broad agreement with the known geographical pattern of As speciation in rice. Rice produced in Bangladesh and China generally contains only small percentages of DMA $(\sim 20 \%),{ }^{5-7}$ whereas rice produced in the south-central states of the U.S. is dominated with DMA (typically 50-60\%). ${ }^{5,7,8}$ In glasshouse 
experiments, the UK soil used in the present study also produced high percentages of DMA in rice grain. ${ }^{2,49}$ When both Asian and American rice cultivars were grown in Arkansas, they all contained high percentages of DMA, ${ }^{55}$ suggesting that it is the environment rather than the rice genotype that gives rise to the geographical pattern in As speciation. Methylated As, especially DMA, is highly mobile during xylem and phloem transport toward rice grain; ${ }^{10,29,56}$ hence, the relative abundance of DMA in rice grain can be further amplified compared to that in the soil pore water.

In conclusion, the present study has revealed considerable variations among soils in As methylation as well as in the copy number and the diversity of the microbial ars $M$ genes. However, As methylation in soil appears to be influenced more by the soil conditions (such as $\mathrm{pH}$ and DOC) than by the ars $M$ copy number, suggesting a strong environmental influence on the activity of As methylating microbes, which warrants further investigations. The fact that As speciation in rice plants reflected that in the soil pore water reinforces the notion that methylated As species in plants originate from the soil.

\section{ASSOCIATED CONTENT}

\section{S Supporting Information}

Information of the locations of soils and selected soil properties; comparison of soil pore water preservation methods for arsenic speciation; relationship between the sum of arsenic species measured by HPLC-ICP-MS and total soluble As measured by ICP-MS in soil pore water; soil redox potential; correlations between bacterial $16 \mathrm{~S}$ rDNA and arsM copy number and soil $\mathrm{pH}$; correlations between methylated As concentration in soil pore water and $\operatorname{ars} M$ copy number, soil $\mathrm{pH}, \mathrm{DOC}$ or inorganic As concentrations; correlations between plant total As or DMA concentrations and soil soluble As or DMA. This material is available free of charge via the Internet at http://pubs.acs.org.

\section{AUTHOR INFORMATION}

\section{Corresponding Author}

*Phone: +86 25 84396509; fax: +86 25 84399551; e-mail: Fangjie.Zhao@njau.edu.cn.

\section{Notes}

The authors declare no competing financial interest.

\section{ACKNOWLEDGMENTS}

This research was financially supported by the Innovative Research Team Development Plan of the Ministry of Education of China (IRT1256), the Priority Academic Program Development of Jiangsu Higher Education Institutions (PAPD) and the 111 project (B12009). Rothamsted Research receives strategic funding from the Biotechnology and Biological Sciences Research Council of the UK.

\section{REFERENCES}

(1) Meharg, A. A.; Zhao, F. J. Arsenic \& Rice; Springer: Dordrecht, 2012; p 171.

(2) Xu, X. Y.; McGrath, S. P.; Meharg, A.; Zhao, F. J. Growing rice aerobically markedly decreases arsenic accumulation. Environ. Sci. Technol. 2008, 42, 5574-5579.

(3) Arao, T.; Kawasaki, A.; Baba, K.; Mori, S.; Matsumoto, S. Effects of water management on cadmium and arsenic accumulation and dimethylarsinic acid concentrations in Japanese rice. Environ. Sci. Technol. 2009, 43 (24), 9361-9367.
(4) Ma, J. F.; Yamaji, N.; Mitani, N.; Xu, X. Y.; Su, Y. H.; McGrath, S. P.; Zhao, F. J. Transporters of arsenite in rice and their role in arsenic accumulation in rice grain. Proc. Nat. Acad. Sci. U.S.A. 2008, 105, 9931-9935.

(5) Williams, P. N.; Price, A. H.; Raab, A.; Hossain, S. A.; Feldmann, J.; Meharg, A. A. Variation in arsenic speciation and concentration in paddy rice related to dietary exposure. Environ. Sci. Technol. 2005, 39 (15), 5531-5540.

(6) Zhu, Y. G.; Sun, G. X.; Lei, M.; Teng, M.; Liu, Y. X.; Chen, N. C.; Wang, L. H.; Carey, A. M.; Deacon, C.; Raab, A.; Meharg, A. A.; Williams, P. N. High percentage inorganic arsenic content of mining impacted and nonimpacted Chinese rice. Environ. Sci. Technol. 2008, 42 (13), 5008-5013.

(7) Meharg, A. A.; Williams, P. N.; Adomako, E.; Lawgali, Y. Y.; Deacon, C.; Villada, A.; Cambell, R. C. J.; Sun, G.; Zhu, Y. G.; Feldmann, J.; Raab, A.; Zhao, F. J.; Islam, R.; Hossain, S.; Yanai, J. Geographical variation in total and inorganic arsenic content of polished (white) rice. Environ. Sci. Technol. 2009, 43, 1612-1617.

(8) Zavala, Y. J.; Gerads, R.; Gürleyük, H.; Duxbury, J. M. Arsenic in rice: II. Arsenic speciation in USA grain and implications for human health. Environ. Sci. Technol. 2008, 42, 3861-3866.

(9) Hansen, H. R.; Raab, A.; Price, A. H.; Duan, G. L.; Zhu, Y. G.; Norton, G. J.; Feldmann, J.; Meharg, A. A. Identification of tetramethylarsonium in rice grains with elevated arsenic content. J. Environ. Monit. 2011, 13 (1), 32-34.

(10) Zhao, F. J.; Zhu, Y. G.; Meharg, A. A. Methylated arsenic species in rice: Geographical variation, origin, and uptake mechanisms. Environ. Sci. Technol. 2013, 47, 3957-3966.

(11) Styblo, M.; Del Razo, L. M.; Vega, L.; Germolec, D. R.; LeCluyse, E. L.; Hamilton, G. A.; Reed, W.; Wang, C.; Cullen, W. R.; Thomas, D. J. Comparative toxicity of trivalent and pentavalent inorganic and methylated arsenicals in rat and human cells. Arch. Toxicol. 2000, 74 (6), 289-299.

(12) Yan, W. G.; Dilday, R. H.; Tai, T. H.; Gibbons, J. W.; McNew, R. W.; Rutger, J. N. Differential response of rice germplasm to straighthead induced by arsenic. Crop Sci. 2005, 45 (4), 1223-1228.

(13) Takamatsu, T.; Aoki, H.; Yoshida, T. Determination of arsenate, arsenite, monomethylarsonate, and dimethylarsinate in soil polluted with arsenic. Soil Sci. 1982, 133 (4), 239-246.

(14) Huang, J. H.; Matzner, E. Dynamics of organic and inorganic arsenic in the solution phase of an acidic fen in Germany. Geochim. Cosmochim. Acta 2006, 70 (8), 2023-2033.

(15) Huang, J. H.; Matzner, E. Mobile arsenic species in unpolluted and polluted soils. Sci. Total Environ. 2007, 377 (2-3), 308-318.

(16) Geiszinger, A.; Goessler, W.; Kosmus, W. Organoarsenic compounds in plants and soil on top of an ore vein. Appl. Organomet. Chem. 2002, 16, 245-249.

(17) Huang, J. H.; Hu, K. N.; Decker, B. Organic arsenic in the soil environment: Speciation, occurrence, transformation, and adsorption behavior. Water, Air, Soil Pollut. 2011, 219 (1-4), 401-415.

(18) Turpeinen, R.; Pantsar-Kallio, M.; Kairesalo, T. Role of microbes in controlling the speciation of arsenic and production of arsines in contaminated soils. Sci. Total Environ. 2002, 285 (1-3), 133-145.

(19) Blodau, C.; Fulda, B.; Bauer, M.; Knorr, K. H. Arsenic speciation and turnover in intact organic soil mesocosms during experimental drought and rewetting. Geochim. Cosmochim. Acta 2008, 72 (16), 3991-4007.

(20) Mestrot, A.; Feldmann, J.; Krupp, E. M.; Hossain, M. S.; Roman-Ross, G.; Meharg, A. A. Field fluxes and speciation of arsines emanating from soils. Environ. Sci. Technol. 2011, 45 (5), 1798-1804.

(21) Mestrot, A.; Uroic, M. K.; Plantevin, T.; Islam, M. R.; Krupp, E. M.; Feldmann, J.; Meharg, A. A. Quantitative and qualitative trapping of arsines deployed to assess loss of volatile arsenic from paddy soil. Environ. Sci. Technol. 2009, 43 (21), 8270-8275.

(22) Cullen, W. R.; Reimer, K. J. Arsenic speciation in the environment. Chem. Rev. 1989, 89 (4), 713-764.

(23) Woolson, E. A.; Kearney, P. C. Persistence and reactions of ${ }^{14} \mathrm{C}$ cacodylic acid in soils. Environ. Sci. Technol. 1973, 7 (1), 47-50. 
(24) Qin, J.; Lehr, C. R.; Yuan, C. G.; Le, X. C.; McDermott, T. R.; Rosen, B. P. Biotransformation of arsenic by a Yellowstone thermoacidophilic eukaryotic alga. Proc. Nat. Acad. Sci. U.S.A. 2009, 106 (13), 5213-5217.

(25) Qin, J.; Rosen, B. P.; Zhang, Y.; Wang, G. J.; Franke, S.; Rensing, C. Arsenic detoxification and evolution of trimethylarsine gas by a microbial arsenite S-adenosylmethionine methyltransferase. Proc. Nat. Acad. Sci. U.S.A. 2006, 103 (7), 2075-2080.

(26) Ye, J.; Rensing, C.; Rosen, B. P.; Zhu, Y. G. Arsenic biomethylation by photosynthetic organisms. Trends Plant Sci. 2012, 17 (3), 155-162.

(27) Yin, X. X.; Chen, J.; Qin, J.; Sun, G. X.; Rosen, B. P.; Zhu, Y. G. Biotransformation and volatilization of arsenic by three photosynthetic cyanobacteria. Plant Physiol. 2011, 156 (3), 1631-1638.

(28) Thomas, D. J.; Rosen, B. P. Arsenic methyltransferases. In Encyclopedia of Metalloproteins; Uversky, V. N.; Kretsinger, R. H., Permyakov, E. A., Eds.; Springer Science+Business Media, 2012.

(29) Lomax, C.; Liu, W. J.; Wu, L. Y.; Xue, K.; Xiong, J.; Zhou, J. Z.; McGrath, S. P.; Meharg, A. A.; Miller, A. J.; Zhao, F. J. Methylated arsenic species in plants originate from soil microorganisms. New Phytol. 2012, 193, 665-672.

(30) He, Z. L.; Gentry, T. J.; Schadt, C. W.; Wu, L. Y.; Liebich, J.; Chong, S. C.; Huang, Z. J.; Wu, W. M.; Gu, B. H.; Jardine, P.; Criddle, C.; Zhou, J. GeoChip: A comprehensive microarray for investigating biogeochemical, ecological and environmental processes. ISME J. 2007, 1 (1), 67-77.

(31) Islam, S. M. A.; Fukushi, K.; Yamamoto, K.; Saha, G. C. Estimation of biologic gasification potential of arsenic from contaminated natural soil by enumeration of arsenic methylating bacteria. Arch. Environ. Contam. Toxicol. 2007, 52 (3), 332-338.

(32) Stroud, J. L.; Khan, M. A.; Norton, G. J.; Islam, M. R.; Dasgupta, T.; Zhu, Y. G.; Price, A. H.; Meharg, A. A.; McGrath, S. P.; Zhao, F. J. Assessing the labile arsenic pool in contaminated paddy soils by isotopic dilution techniques and simple extractions. Environ. Sci. Technol. 2011, 45, 4262-4269.

(33) Bednar, A. J.; Garbarino, J. R.; Ranville, J. F.; Wildeman, T. R. Preserving the distribution of inorganic arsenic species in groundwater and acid mine drainage samples. Environ. Sci. Technol. 2002, 36 (10), 2213-2218.

(34) Gault, A. G.; Jana, J.; Chakraborty, S.; Mukherjee, P.; Sarkar, M.; Nath, B.; Polya, D. A.; Chatterjee, D. Preservation strategies for inorganic arsenic species in high iron, low-Eh groundwater from West Bengal, India. Anal. Bioanal. Chem. 2005, 381 (2), 347-353.

(35) Li, R. Y.; Ago, Y.; Liu, W. J.; Mitani, N.; Feldmann, J.; McGrath, S. P.; Ma, J. F.; Zhao, F. J. The rice aquaporin Lsil mediates uptake of methylated arsenic species. Plant Physiol. 2009, 150, 2071-2080.

(36) Jia, Y.; Huang, H.; Zhong, M.; Wang, F. H.; Zhang, L. M.; Zhu, Y. G. Microbial arsenic methylation in soil and rice rhizosphere. Environ. Sci. Technol. 2013, 47 (7), 3141-3148.

(37) Zhou, J. Z.; Bruns, M. A.; Tiedje, J. M. DNA recovery from soils of diverse composition. Appl. Environ. Microbiol. 1996, 62 (2), 316322.

(38) Masscheleyn, P. H.; Delaune, R. D.; Patrick, W. H. Effect of redox potential and $\mathrm{pH}$ on arsenic speciation and solubility in a contaminated soil. Environ. Sci. Technol. 1991, 25 (8), 1414-1419.

(39) Takahashi, Y.; Minamikawa, R.; Hattori, K. H.; Kurishima, K.; Kihou, N.; Yuita, K. Arsenic behavior in paddy fields during the cycle of flooded and non-flooded periods. Environ. Sci. Technol. 2004, 38 (4), 1038-1044.

(40) Yamaguchi, N.; Nakamura, T.; Dong, D.; Takahashi, Y.; Amachi, S.; Makino, T. Arsenic release from flooded paddy soils is influenced by speciation, Eh, $\mathrm{pH}$, and iron dissolution. Chemosphere 2011, 83, 925-932.

(41) Onken, B. M.; Hossner, L. R. Determination of arsenic species in soil solution under flooded conditions. Soil Sci. Soc. Amer. J. 1996, 60 (5), 1385-1392.

(42) Tufano, K. J.; Fendorf, S. Confounding impacts of iron reduction on arsenic retention. Environ. Sci. Technol. 2008, 42 (13), $4777-4783$.
(43) Tufano, K. J.; Reyes, C.; Saltikov, C. W.; Fendorf, S. Reductive processes controlling arsenic retention: Revealing the relative importance of iron and arsenic reduction. Environ. Sci. Technol. 2008, 42 (22), 8283-8289.

(44) Huysmans, K. D.; Frankenberger, W. T. Evolution of trimethylarsine by a penicillium sp isolated from agricultural evaporation pond water. Sci. Total Environ. 1991, 105, 13-28.

(45) Carbonell-Barrachina, A. A.; Jugsujinda, A.; Burlo, F.; Delaune, R. D.; Patrick, W. H. Arsenic chemistry in municipal sewage sludge as affected by redox potential and $\mathrm{pH}$. Water Res. 2000, 34 (1), 216-224.

(46) Huang, H.; Jia, Y.; Sun, G. X.; Zhu, Y. G. Arsenic speciation and volatilization from flooded paddy soils amended with different organic matters. Environ. Sci. Technol. 2012, 46 (4), 2163-2168.

(47) Jia, Y.; Huang, H.; Sun, G. X.; Zhao, F. J.; Zhu, Y. G. Pathways and relative contributions to arsenic volatilization from rice plants and paddy soil. Environ. Sci. Technol. 2012, 46 (15), 8090-8096.

(48) Shimizu, M.; Arai, Y.; Sparks, D. L. Multiscale assessment of methylarsenic reactivity in soil. 2. Distribution and speciation in soil. Environ. Sci. Technol. 2011, 45 (10), 4300-4306.

(49) Li, R. Y.; Stroud, J. L.; Ma, J. F.; McGrath, S. P.; Zhao, F. J. Mitigation of arsenic accumulation in rice with water management and silicon fertilization. Environ. Sci. Technol. 2009, 43, 3778-3783.

(50) Frankenberger, W. T. Effects of trace elements on arsenic volatilization. Soil Biol. Biochem. 1998, 30 (2), 269-274.

(51) Bright, D. A.; Brock, S.; Cullen, W. R.; Hewitt, G. M.; Jafaar, J.; Reimer, K. J. Methylation of arsenic by anaerobic microbial consortia isolated from lake sediment. Appl. Organomet. Chem. 1994, 8 (4), $415-422$.

(52) Huang, J. H.; Scherr, F.; Matzner, E. Demethylation of dimethylarsinic acid and arsenobetaine in different organic soils. Water Air Soil Pollut. 2007, 182 (1-4), 31-41.

(53) Gao, S.; Burau, R. G. Environmental factors affecting rates of arsine evolution from and mineralization of arsenicals in soil. J. Environ. Qual. 1997, 26 (3), 753-763.

(54) Yoshinaga, M.; Cai, Y.; Rosen, B. P. Demethylation of methylarsonic acid by a microbial community. Environ. Microbiol. 2011, 13, 1205-1215.

(55) Pillai, T. R.; Yan, W. G.; Agrama, H. A.; James, W. D.; Ibrahim, A. M. H.; McClung, A. M.; Gentry, T. J.; Loeppert, R. H. Total grainarsenic and arsenic-species concentrations in diverse rice cultivars under flooded conditions. Crop Sci. 2010, 50 (5), 2065-2075.

(56) Carey, A. M.; Scheckel, K. G.; Lombi, E.; Newville, M.; Choi, Y.; Norton, G. J.; Charnock, J. M.; Feldmann, J.; Price, A. H.; Meharg, A. A. Grain unloading of arsenic species in rice. Plant Physiol. 2010, 152 (1), 309-319. 